\title{
Combatiendo las enfermedades mitocondriales: estrategias para el desarrollo de terapias génicas y estrategias de prevención
}

\author{
Ongoing strategies against mitochondrial diseases: prevention and development \\ of genetic therapies
}

\author{
Diego González Halphen*
}

\begin{abstract}
Las mitocondrias son organelos que están presentes en el citosol de la mayoría de los organismos eucariontes. Representan la principal fuente de energía metabólica de la célula, generando el ATP (adenosíntrifosfato) a través de la cadena respiratoria y la ATP sintasa, en un fenómeno conocido como fosforilación oxidativa. Las mitocondrias también participan en otros procesos metabólicos como la síntesis de cofactores, la síntesis de ácidos grasos, la regulación del metabolismo, el control del ciclo celular, el envejecimiento y la muerte celular programada. Estos organelos se originaron hace aproximadamente 2,500 millones de años, cuando una alfa-proteobacteria fue engullida por otra célula, probablemente un arqueón (arqueobacteria), estableciéndose una relación simbiótica entre ambos microorganismos. Con el tiempo, las alfa-proteobacterias intracelulares fueron transfiriendo su material genético al núcleo del hospedero, convirtiéndose eventualmente en organelos de la célula eucarionte. Por eso, las mitocondrias actuales conservan remanentes de su origen bacteriano, entre otros, la presencia de un pequeño genoma que en el humano es una molécula circular de 16,600 pares de bases que aquí denominaremos DNA mitocondrial (DNAmt). La información que contiene este material genético representa menos del $0.2 \%$ de la información genética total que tiene una célula; el restante $99.8 \%$ se encuentra en los cromosomas nucleares (alrededor de 19,000 genes que codifican proteínas). EI DNAmt humano contiene 37 genes que codifican RNAs ribosomales, RNAs de transferencia y 13 proteínas que participan en la fosforilación oxidativa. Estas proteínas membranales, todas altamente hidrofóbicas, se sintetizan en ribosomas mitocondriales, se integran a la membrana interna mitocondrial y se ensamblan en alguno de los complejos de la fosforilación oxidativa. El resto de las 1,500 a 2,000 proteínas que se pueden encontrar en una mitocondria están codificadas en el genoma nuclear, se sintetizan en el citosol y se in-
\end{abstract}

troducen a la mitocondria a través de una maquinaria constituida por receptores y transportadores proteicos ubicados en las membranas mitocondriales. Así, la mitocondria importa más del $99 \%$ de las proteínas que requiere para funcionar, sintetizando por sí misma únicamente una docena de proteínas, que sin embargo, juegan un papel esencial en la fosforilación oxidativa. En este sentido, me gusta asemejar a la mitocondria con un país petrolero, ya que este último tiene que importar todos sus insumos a cambio de exportar energía (petróleo o ATP).

Como todo material genético, el DNAmt está sujeto a sufrir mutaciones, algunas de las cuales pueden dar lugar a una gama heterogénea de enfermedades humanas denominadas síndromes mitocondriales o encéfalo-miopatías mitocondriales. Estas enfermedades afectan principalmente a órganos y tejidos con una alta demanda energética, como es el cerebro, los músculos y el sistema endocrino. Entre sus manifestaciones clínicas se incluyen debilidad muscular, intolerancia al ejercicio, ceguera, retraso mental, demencia, epilepsia progresiva, neuropatías sensoriales, ataxia y disfunción renal. Las alteraciones mitocondriales también se han relacionado con otros defectos metabólicos como la diabetes, la obesidad, enfermedades cardiovasculares, enfermedades neurodegenerativas y el cáncer. Las enfermedades mitocondriales no se limitan a la presencia de mutaciones en el DNAmt, también pueden ser causadas por mutaciones en el DNA nuclear, sobre todo aquellas que afectan la estructura y función de proteínas que eventualmente se internalizarán en la mitocondria. Aquí nos enfocaremos únicamente en los defectos en el DNAmt.

\footnotetext{
* Instituto de Fisiología Celular, UNAM.
}

Este artículo puede ser consultado en versión completa en http://www.medigraphic.com/facultadodontologiaunam 
El DNAmt se hereda por vía materna. Así, los humanos tenemos el mismo DNAmt que nuestra madre, que nuestra abuela, que nuestra bisabuela... Esto se debe a que las mitocondrias se encuentran acomodadas solamente en el cuello del espermatozoide y son destruidas selectivamente en el interior del óvulo, por lo que en general, no existe una contribución genética del DNAmt paterno durante la fecundación. Así, se han descrito varios linajes familiares con alteraciones mitocondriales que presentan un claro patrón de herencia materna.

Hasta la fecha se han reportado más de 500 mutaciones puntuales en genes mitocondriales y varias ablaciones y duplicaciones del DNAmt que se han relacionado con padecimientos en humanos. Estudios epidemiológicos han demostrado que alrededor de 1 de cada 6,500 individuos presenta mutaciones patogénicas en el DNAmt. Las mitocondrias no se forman nuevamente en la célula, sólo pueden formarse por el crecimiento y división de estos mismos organelos ya preexistentes. Aunque en la célula en realidad existe un retículo mitocondrial que se está fusionando y fisionando continuamente, se estima que hay alrededor de 10 copias de DNAmt en cada mitocondria y que existen entre 100 y 1,000 mitocondrias por célula (es por esto que el DNAmt también es útil en las ciencias forenses, ya que hay más copias de DNAmt que del DNA nuclear y por lo tanto, es posible identificar material genético en muestras que se encuentran en pequeñas cantidades, como un bulbo de cabello). Para que una enfermedad mitocondrial se manifieste, la mutación en un gen mitocondrial debe estar presente en al menos el $90 \%$ de la población de DNAmt. A pesar de que ya existen las herramientas para transformar el DNA nuclear y existen múltiples protocolos de terapias génicas en marcha, hoy por hoy no existen técnicas que permitan transformar el DNAmt de organismos multicelulares, por lo que no es posible corregir directamente mutaciones en el DNAmt humano. La transformación del DNAmt en organismos multicelulares sigue siendo un reto tanto para la investigación básica como para la clínica. Por lo mismo, tampoco existen tratamientos para las enfermedades mitocondriales, excepto en aquellos casos raros en los que la mutación en el DNAmt se encuentra solamente en un órgano en particular y que sea posible llevar a cabo un trasplante del mismo. El resto de las medidas terapéuticas utilizadas, como el ejercicio físico y diversos tratamientos farmacológicos, son únicamente paliativas, ya que solamente mitigan algunos de los síntomas. La ausencia de tratamientos efectivos para las enfermedades mitocondriales, han llevado a explorar diversas estrategias para desarrollar futuras terapias génicas:
1. Inhibición selectiva de la propagación del DNAmt mutante. Este enfoque intenta introducir a la mitocondria enzimas capaces de reconocer y cortar específicamente al DNAmt mutante. Se espera que así, solamente se siga propagando el DNAmt sin mutaciones.

2. Vectores de expresión mitocondriales. Consistiría en introducir DNAmt recombinante en el organelo, ya sea completo o en fragmentos, que contenga una copia silvestre del gen cuya expresión sea controlada por promotores de genes mitocondriales. Ésta es una opción puramente teórica, ya que como se dijo anteriormente, a la fecha no es posible transformar mitocondrias en organismos multicelulares vivos.

3. Expresión alotópica. Expresar los genes mitocondriales desde el núcleo y que la proteína silvestre sintetizada en el citosol se internalice en la mitocondria aprovechando la maquinaria natural de importación de proteínas.

La expresión alotópica se considera una de las opciones más viables para el tratamiento genético de las enfermedades causadas por mutaciones en el DNA$\mathrm{mt}$; existen ya técnicas establecidas para introducir material genético en el núcleo celular (utilizando diversos vectores adenovirales), por lo que en principio, la proteína resultante llegaría a todas las mitocondrias presentes en la célula afectada. El gen que se pretende expresar alotópicamente debe ser modificado de tal manera que sea capaz de expresarse desde el núcleo. Debe tomarse en cuenta que en los humanos el código genético y el uso de codones mitocondriales son diferentes a los nucleares, por ejemplo, el codón UAG que codifica para triptófano de acuerdo con el código genético mitocondrial es interpretado como un codón de paro en el código genético nuclear. Por lo tanto, el gen mitocondrial debe rediseñarse para que el RNA mensajero correspondiente sea traducido correctamente por los ribosomas citosólicos. Después de ser sintetizada, la proteína deberá dirigirse a la mitocondria; para ello, requiere de una secuencia señal en el extremo amino terminal, denominada señal de direccionamiento a la mitocondria. Estas señales están constituidas por una cadena polipeptídica de 20 a 30 aminoácidos que funciona como un código postal, asegurando el envío de la proteína sintetizada en el citosol a la mitocondria y no a algún otro organelo en la célula. La señal es reconocida por el complejo transportador de proteínas ubicado en las membranas externa e interna de las mitocondrias. Después de atravesar las dos membranas mitocondriales y llegar a la matriz mitocondrial, la señal es removida por una 
proteasa específica, dando lugar a la proteína madura. Una estrategia alternativa, que se ha desarrollado en los últimos años, es permitir que ingresen a la mitocondria RNAs mensajeros, los cuales parecen importarse a través de la misma maquinaria con la que se transportan a las proteínas cuyo destino final es la mitocondria. Estos RNAs mensajeros también cuentan con señales específicas que los dirigen a la mitocondria. Una vez en la matriz mitocondrial, el RNA mensajero podría traducirse y sintetizar a la proteína correspondiente en los propios ribosomas mitocondriales. Así, la proteína podrá integrarse directamente a la membrana interna mitocondrial e incorporarse al complejo de la fosforilación oxidativa que le corresponda.

Hasta el momento, no existe entonces una terapia efectiva para las enfermedades mitocondriales. Sin embargo, en los últimos años han surgido alternativas interesantes de prevención. El primero es simplemente un diagnóstico prenatal, que le permitirá a una pareja decidir si tiene o no hijos. La segunda es la transferencia del complejo huso-acromático, una tecnología basada en el intercambio de material genético y en técnicas de fertilización in vitro. Cuando existe evidencia clara de una mutación mitocondrial asociada con una enfermedad mitocondrial en una mujer, hoy por hoy existe la tecnología para evitar que la mutación se herede. Esta tecnología se basa en los trabajos pioneros de Tachibana ${ }^{1,2}$ y colaboradores, primero con primates y luego con células humanas, realizados en instituciones de Oregón, EUA (Tachibana y col., 2009; 2013). ${ }^{2}$ Esencialmente, se toman óvulos de una mujer donante (con mitocondrias sanas, sin mutaciones) y de la mujer con mutaciones en el DNAmt (la madre que desea tener un hijo sano). Se retira el huso acromático (el conjunto de microtúbulos que van desde los centrómeros de los cromosomas hacia los centriolos en los polos durante la meiosis) del óvulo de la donante, es decir, se elimina todo el material genético nuclear presente en el óvulo. Por otra parte, también se retira el huso acromático de la futura madre con mutaciones mitocondriales y se transfiere al óvulo de la donante. De tal manera que se generan óvulos «reconstruidos» que tendrán el material genético nuclear de la madre (intacto) y el material genético mitocondrial de la donante (intacto). El óvulo reconstruido se fertiliza in vitro y se permite el desarrollo de la embriogénesis hasta el momento en que pueda implantarse en el útero materno. De ahí procede un embarazo normal que dará lugar a un bebé sano, que tendrá el $49.9 \%$ del material genético cromosómico del padre, el $49.9 \%$ del material genético cromosómico de la madre y únicamente el $0.2 \%$ del material genético (el DNA mitocondrial) de la donante. Por lo tanto no es estrictamente cierto que el bebé sea producto de «tres padres», aunque si representa un mosaico genético de tres personas. El 3 de febrero de este año, la Cámara de los Comunes del Reino Unido, ha dado la luz verde para que esta técnica se utilice en la clínica, dándoles la oportunidad a mujeres con mutaciones mitocondriales a tener progenie sana. Así, Gran Bretaña se ha convertido en el primer país que permite que las técnicas de fertilización in vitro, utilicen el material genético de una "segunda madre» para reparar DNA mitocondrial mutado. Sin duda, esto es otro ejemplo en el cual la prevención avanza más rápido que la curación. Gran Bretaña también es un ejemplo para muchos países, incluido el nuestro, al legislar de forma expedita para poner los avances científicos y tecnológicos al servicio de sus ciudadanos a la brevedad posible y no con un rezago que puede ser de décadas.

A pesar de los avances espectaculares en la prevención de las enfermedades mitocondriales, la expresión alotópica sigue siendo un reto intelectual y experimental que amerita seguir estudiándose, para eventualmente sentar las bases para desarrollar una terapia génica que pueda dar esperanza a los pacientes que sufren un síndrome mitocondrial.

\section{REFERENCIAS}

1. Tachibana $\mathrm{M}$ et al. Mitochondrial gene replacement in primate offspring and embryonic stem cells. Nature. 2009; 461 (7262): 367-372.

2. Tachibana $\mathrm{M}$ et al. Human embryonic stem cells derived by somatic cell nuclear transfer. Cell. 2009; 153 (6): 1228-1238.

Dirección para correspondencia: Diego González Halphen

E-mail: dhalphen@correo.ifc.unam.mx 